\title{
Aut idem - Unsinn nicht nur für Allergiker!
}

\author{
Die Politik, und hier federführend die Gesundheitsministerin Ulla \\ Schmidt, hat die Aut-idem-Regelung im Arzneiausgaben- \\ begrenzungsgesetz (AABG) wider besseren Wissens durchgesetzt \\ und somit die Arbeitsweise der niedergelassenen Ärzte weiter er- \\ schwert. Das Chaos wird größer.
}

\begin{abstract}
$D_{A}^{a}$ as Motto lautet: Der „dumme“ Arzt verordnet ein teures Medikament; der „schlaue“ Apotheker gibt ein gleichwertiges, preiswerteres Medikament ab. Dadurch sollen Millionen gespart werden.

Dem kann der Arzt - wenn er seine Therapiehoheit behalten will - dann nur dadurch entgehen, wenn er Nonaut-idem ankreuzt (hierfür gibt es noch gar keinen Rezeptvordruck. Der Arzt muss derzeit das ankreuzen, was er nicht will, nämlich das Aut-idem-Feld).

Oder der Arzt benutzt einen (kleinen) Stempel: Keine Substitution! Dieser Stempel muss hinter jeder der drei auf einem Rezept möglichen Rezepturen gestempelt werden.

Der Apotheker muss substituieren, wenn der Arzt nicht

- generisch verordnet,

- preisgünstig verordnet,

- aut idem ausschließt.
\end{abstract}

\section{Was ist das untere Preisdrittel?}

Aut idem betrifft nur den arzneilich wirksamen Wirkstoff. Eine Liste mit austauschbaren arzneilichen Wirkstoffen existiert noch nicht und wird vollständig auch nie existieren. Als Substitution werden Produkte der Preisspanne einer Arznei im untersten Drittel abgegeben, wobei in diesem untersten Drittel fünf Produkte enthalten sein müssen.

Es ist durchaus vorstellbar, dass verschiedene Firmen so genannte Dummys anmelden und in den Markt geben werden, d.h. es werden sehr teure Produkte einer bereits bekannten Arznei angeboten, bei denen den Firmen klar ist, dass sie kaum oder gar nicht verordnet werden. Aber sie verändern die Preisspanne, so dass sich auch das unterste Drittel dadurch ständig verändern kann.

Die Durchsetzung der Aut-idemRegelung kann der Beginn des Endes der ärztlichen Therapiehoheit sein. Die Auswirkungen für die Patienten können

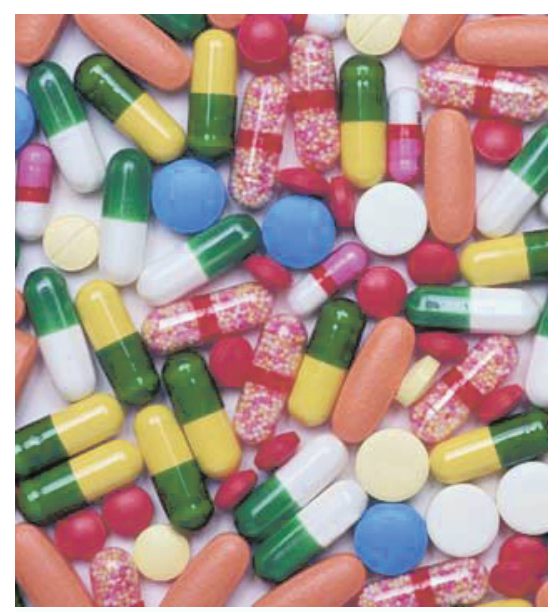

Nicht nur für Allergiker sind Füll- und Hilfsstoffe von Arzneimittelzubereitungen von Bedeutung

erheblich sein. Heute eine große und morgen eine kleine Tablette oder gar Kapsel? Heute eine rot-grüne und morgen vielleicht eine schwarz-gelbe Kapsel? Das führt zur Verunsicherung und evtl. Nichteinnahme von Medikamenten.

\section{Aut-idem-Risiko für Allergiker besonders hoch!?}

Besonders gefährdet sind Allergiker; denn Unverträglichkeitsreaktionen können nicht nur durch einen Wirkstoff, sondern auch durch die - je nach Generika unterschiedlichen - Zusatz- oder Hilfsstoffe ausgelöst werden. Muss daher für Allergiker eine Freistellung für Aut idem gefordert werden? Wenn ja, wer legt fest, welcher Patient prädisponiert ist, und wie kann er erfasst werden?

Die Haftungssituation bleibt unklar. Der Arzt haftet auch, wenn er Aut idem nicht ausgeschlossen hat. Die Rechtsgrundlage der Wirtschaftlichkeit wankt.

Es ist ein Kreuz mit dem Kreuz!

\section{Rolle des Apothekers ist überzogen}

Und schließlich muss gefragt werden, was steuert die Entscheidung des Apothekers, der in erster Linie als Händler und Verkäufer agiert? Abgesehen von den erforderlichen Kenntnissen, die er nicht haben kann, kann er auch nicht die Zeit aufwenden, jeden Aut-idemFall persönlich zu betreuen. Der Apotheker kann nicht als objektiver Hüter für diese neue Regelung fungieren.

\section{Wirkstoffgleichheit ist nicht gleich Bioäquivalenz}

$\mathrm{Zu}$ guter Letzt fordern namhafte Pharmazeuten, dass bei vielen Arzneimittelgruppen nur dann substituiert werden darf, wenn für das vorgesehene Fertigarzneimittel allgemein zugängliche, zuverlässige Bioäquivalenzdaten vorliegen. Das betrifft u.a. auch die Antiasthmatika. Für wie viele Dosier-Aerosole und Pulverinhalatoren sind jeweils die Bioäquivalenz bzw. die therapeutische Gleichwertigkeit belegt?

Die Pharmazeuten halten den Vorschlag der Bundesärztekammer für völlig inakzeptabel, Filmtabletten, Kapseln und Dragees als austauschbar einzustufen.

Viele Verbände und Organisationen rufen aufgrund der angerissenen Problematik dazu auf, Aut idem zunächst nicht anzuwenden und quasi zu boykottieren. Dem steht entgegen, dass die Regelung formal seit dem 23.2.02 Gültigkeit hat.

\section{Fazit}

Das Chaos ist vergrößert worden - gespart wird unter dem Strich

NICHTS!

Dr. W. Kersten, Moers 